\title{
Emerging Issues in the Utilization of Synchronous ICT in the Delivery of Distance Education at Public Universities in Uganda
}

\author{
Rita Nankanja ${ }^{1}$ and Ronald Bisaso ${ }^{2}$ \\ ${ }^{1}$ East African Institute of Higher Education Studies and Development, \\ Makerere University, Uganda \\ ritanankanja@yahoo.com \\ ${ }^{2}$ Higher Education Group, University of Tampere, Finland \\ ronald.bisaso@uta.fi
}

\begin{abstract}
This paper reports on the utilization of synchronous information and communication technologies (ICT) in the delivery of distance education at the two largest public universities in Uganda. This was an exploratory descriptive survey that aimed at establishing the emerging issues in the utilization. Applying Peter's theory of industrialization of distance education and Moore's theory of transactional distance as interpretive frameworks, the findings illuminate variations in ICT usage for communication among the learners, and with their instructors. This nascent use of ICT was mainly supported by telephones as well as text-based chat and projectors, but on a smaller scale. It was concluded that learners and instructors should be given training in basic utilization of the available and accessible synchronous ICT. Besides, more studies on the changing patterns of distance education in Ugandan universities and comparative studies with other African universities concerning their distance education trajectories were needed.
\end{abstract}

Keywords: Transactional distance, distance education, synchronous ICT.

\section{Introduction}

Integration of ICT into distance education in Uganda has been on a small scale and distance education has been limited to first generation approaches such as print and face-to-face sessions. But this trend has been changing with the emergence of ICTrelated project initiatives by the WorlDLinks in schools and ConnectED in Teachers' colleges to integrate ICT in teaching and learning through distance education (Aguti and Fraser, 2006; Bbuye and Mango, 2005). Related developments have shown that Uganda is one of the countries with active markets for the Internet, which is a valuable tool in distance education. Moreover, the two largest Ugandan public universities in terms of enrolment and distance education programmes have enhanced their ICT infrastructure pertinent to distance education (Aguti and Fraser, 2006; Binns and Otto, 2006; Mayende, 2007; Saint, 1999). Despite these budding developments in ICT for distance education, little systematic inquiry has been done on the interactive 
processes between the learners, and between the learners and their instructors. Additionally, while this current study builds on available research evidence, unlike some of the earlier studies, it takes a theoretical orientation by applying two theoretical frameworks to interpret the emerging issues in the utilization of synchronous ICT in distance education. In this paper, synchronous ICT denotes the direct exchange or real time communication between teachers and learners and includes text-based chat, videoconferencing, projectors and telephone. Distance education has been defined as an education process in which a significant portion of the teaching is conducted by someone removed in space and/or time from the learner (Perraton and Robinson, 2002). Thus, we attempt to answer the question "how does synchronous ICT facilitate distance education in public universities in Uganda?" The rest of the paper is structured as follows. First, the theoretical framework is provided. Second, the methods used in gathering evidence are discussed. Third, the findings from the study are given and fourth, conclusions are made.

\section{Theoretical Framework}

Peters' (1994) Theory of Industrialization of Distance Education portrays the role of mechanization in distance education and indicates that distance education cannot take place without the use of machines. Examples such as duplicating machines and transport systems are pre-requisites to distance education and additional facilities of modern means of communication and electronic data-processing installations are later forms of distance teaching. Therefore machines which are in this case ICT are inseparable with distance education. Peters suggests that machines ensure efficient dissemination of knowledge and education becomes accessible to as many people as possible. Moore's (1996) Theory of Transactional Distance entails dialogue, structure and autonomy of learners in distance education and therefore it is used to explain the relationship between ICT and distance education. It looks at the real teaching and learning process and how it is done in distance education. The transaction which here is the communication between the teachers and the learners is explained in terms of dialogue that is the way in which the communication is carried out; structure, which is how the program is designed to accommodate all learners' needs; and learner autonomy that implies the degree to which learners can learn on their own. In this case, ICT is presumed to be useful in the transactional distance between the learner and fellow learners and between the learner and the teacher. In other words, dialogue, structure and autonomy in the process of all these interactions during distance education can be interpreted as being facilitated by ICT. Recent studies on the use of synchronous ICT in distance education have evaluated ICT in terms of flexibility, improving perceptions about instructional approaches and efficacy in terms of levels of cognitive process and meta-cognition in distance teacher education in Uganda (Gudula, 2006). Prior to this, Ouma (2003) found out that emphasis was on ICT for enhancing face-to-face delivery and that Makerere and Kyambogo Universities were advancing towards introducing ICT in the management and teaching/learning processes. Building on these earlier studies, we concentrate on the role of the budding 
synchronous ICT infrastructure and resources in reducing the transactional distance in the teaching and learning process in distance education. In this study, synchronous ICT was conceptualized in terms of telephone, text-based chat, video conferencing and projectors while distance education was conceptualized as the use of print, face to face sessions, student groups and individualized learning. It was hypothesized that the ICT resources enhance dialogue, provide better structure and promote autonomy in distance education.

\section{Methods}

This was an exploratory descriptive survey in which self-administered questionnaires and structured interview guides were designed and distributed to the students and lecturers respectively. The instruments were designed in such a way that they had a main title, an introduction to the study which included background information, a section on ICT (independent variable) synchronous ICT and the last section on distance education (dependent variable). The population of students on distance education in Makerere university was approximately 6000 (Aguti, 2006) and in Kyambogo University there were over 5026 distance education students (Binns and Otto, 2006). According to Krejcie and Morgan (1970), with a population of 11,000, the sample should be 370 . Out of the 370 targeted respondents, a total of 188 students responded and 10 lecturers were interviewed out of the approximated 20 in both universities. Data was collected from both students and lecturers of distance education. Students are those in Makerere University offering Bachelor of Science, Bachelor of Commerce and Bachelor of Education and those in Kyambogo University offering Diploma in Education- primary (External) and Diploma in Special Needs Education (External). Data obtained using questionnaires was analyzed by use of frequency distributions generated through the use of Epi-data and Statistical Package for Social Scientists (SPSS) software package. Interview data was coded and emerging themes were identified.

\section{Findings}

A number of questions were put to both the instructors and the students from Makerere and Kyambogo universities, to find out if they really use these ICT, what they use them for and if they do not, why. Over $63 \%$ of the students were from Makerere University and about $37 \%$ of the students were from Kyambogo University. The difference was mainly due to the fact that there are more students and at the same time, more courses offered through distance education at Makerere compared to Kyambogo. Male respondents comprised $57 \%$ whereas $43 \%$ were female. Over $70 \%$ of the respondents were below 30 years of age, $24 \%$ between the age of 30 and 45 , while only one per cent was over the age of 45 years. The modal age of the students is below 30 years which implies that majority of those who are currently upgrading through distance education are quite young. This may also be attributed to the 
increasing demand for higher education in the recent years by secondary school leavers as seen in the rising enrolments in universities. Out of all the students contacted, about 39\% were offering Bachelor of Education followed by those of the Diploma in Education Primary (External). Bachelor of commerce (B COM) and Bachelor of education (BED) are courses offered at Makerere University in the distance education department. Diploma in Education Primary (External) (DEPE) and Diploma in Special Needs Education (DSNEE) are courses offered at Kyambogo University distance education department. Table 1 shows the percentage of students participating in the study enrolled in the different courses. All these courses utilize these ICT. According to the table, majority of the respondents were offering Bachelor of Education, Diploma in Education Primary (External) and Bachelor of Commerce.

Table 1. Respondents in the different Distance Education Courses

\begin{tabular}{|c|c|c|c|c|c|}
\hline & B COM & BED & DEPE & DSNEE & Total \\
\hline Frequency & 47 & 74 & 63 & 4 & 188 \\
\hline Percentage & 25 & 39 & 34 & 2 & 100 \\
\hline
\end{tabular}

Throughout the different courses these respondents were currently offering, they were asked their years of study and $29 \%$ of the respondents were in their first year. In second year we had around $18 \%$ of the respondents and $41 \%$ of the respondents were actually in their third year. A small percentage was in their fourth year and that is about $12 \%$ of all the respondents. The respondents were again asked their highest level of education so far and 34\% of them had acquired certificates, 53\% had a diploma, while those who had attained a degree status were over $12 \%$ of the respondents. A small percentage of the students, $0.5 \%$ had a post graduate diploma as their highest level of education so far attained.

Synchronous ICT involved here are telephones, text- based chat, video conferencing and projectors. Telephones are highly used in distance education according to both students and instructors. Approximately $76 \%$ of the students showed that they use telephones as shown in Figure 1 and about the same percentage of instructors (70\%) also showed their use of telephones. These mainly are mobile telephones that are used in the communication between the learners and instructors. This is probably because mobile telephones have got a wider coverage and are convenient for any location. Besides, the information exchanges are synchronous since they involve real time communication between the instructors and the learners and between the learners themselves.

Considering Text based chat which is a two way communication involving the use of text, it has low utilization according to the responses obtained during the research. Actually only around $30 \%$ of the students show its utilization. Over $60 \%$ of the instructors on the other hand indicate its usage. However, most of the respondents who say they use text based chat might mean the use of Short Message Service (SMS) because text-based chat technology is not so much in use in Uganda and 


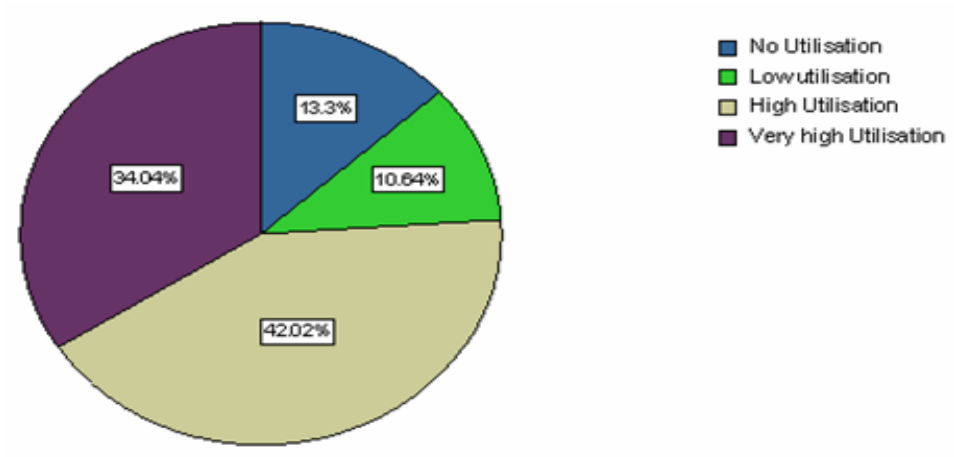

Fig. 1. Utilization of telephones in distance education by students

especially in both Makerere and Kyambogo universities for distance education. Video conferencing involves communication between the learners and instructors using a video but in any case it is easy for the learners to communicate directly to their instructors. This is not common in Uganda and in this case, it is also not used in distance education in our universities. A limited percentage of students (about 20\%) show that they use it in their studies. This is not in line with what prevails at the universities or the study centres. This might mean that the respondents use this type of ICT in their other business and not in education. Instructors on the other hand do not show any use of video conferencing in their delivery and development of distance education.

Projectors are mainly used for communication between the instructor and a large group of students. It conveys the message to a big number of students and it is controlled by the instructor. The students get a chance to ask for clarification there and then. There is little utilization of the projectors in distance education in Ugandan universities. Only $20 \%$ of the students show their use of projectors though about $40 \%$ of the instructors show that they use them. When asked as to why there is no or low utilization of synchronous ICT especially video conferencing, instructors had reasons to give which include, the lack of video conferencing facilities though these have been found at the Uganda Management Institute in Uganda, ICT not being properly developed in Ugandan universities and computer literacy still being low among others. The utilization of synchronous ICT has been curtailed by the fact that the current nature of distance education has been mainly first-generation that is, print and second-generation, face-to-face and less on the other forms of distance education. Therefore, the synchronous ICT like telephones, projectors, text-based chat and video conferencing that would have been exploited to enhance distance education have been underutilized. Students and instructors were contacted to present their opinions on the purpose of synchronous ICT in distance education in both Kyambogo and Makerere universities. The purposes were access to learning materials, interaction with the instructor, interaction with other students, assessment and research and these were rated accordingly by both students and instructors. Table 2 below shows how instructors rated the purpose of ICT to their delivery and development of distance education. 
Table 2. The purpose of synchronous ICT in distance education as rated by the Instructors

\begin{tabular}{|r|c|c|c|c|c|}
\hline & $\begin{array}{l}\text { Access to } \\
\text { teaching } \\
\text { materials }\end{array}$ & $\begin{array}{l}\text { Interaction } \\
\text { with other } \\
\text { instructors }\end{array}$ & $\begin{array}{c}\text { Interaction } \\
\text { with } \\
\text { students }\end{array}$ & Assessment & Research \\
\hline Frequency & 8 & 6 & 8 & 6 & 8 \\
\hline Missing & 1 & 1 & 1 & 2 & 1 \\
\hline
\end{tabular}

Most instructors agree that synchronous ICT are important in the delivery and development of distance education as shown in Table 2.

Therefore:

a. Students and instructors utilize synchronous ICT on a large scale

b. Telephones and text based chat (can be taken to mean SMS) are the most highly utilized synchronous ICT by both students and instructors

c. The utilization of synchronous ICT by students does not vary much from the utilization of synchronous ICT by instructors

d. The main reason for none or low utilization of synchronous ICT especially video conferencing and projectors is because they are not available and those which are available are inaccessible.

e. Most students give the main purposes of synchronous ICT as being to interact with other students and also to access learning materials. Instructors give the main purposes of synchronous ICT as being to access teaching materials, to interact with students and to do research.

f. For purposes of accessing learning materials, interaction, assessment and research in distance education, students use synchronous ICT more than instructors.

Respondents were also asked on their learning activities in distance education and a lot was gleaned from them. Printed material is used mostly by instructors and students find it easy to follow it. Again, most of the students do not find problems in face to face sessions as they can understand the content delivered and follow the instructors as well as refer to the content given later. Most instructors also find it easy to develop content for face to face sessions, deliver it and refer to it later. Most of the students can again understand the content given on their own, can follow that given by instructors later on their own and find it easy to add on it later on their own. Most instructors $(50 \%)$ however say that it is not easy for students to refer to content given on their own. However, they say that it is easy for these students to search for content to add on that delivered to them. Most of the students find it easy to understand content given in organized study groups and can always refer to content given in class in their organized study groups and can search for more to add on in these groups. Instructors also agree with students that it is easy to understand content given in organized study groups and to refer and add to it later in these groups. With reference to audio methods like the use audio cassettes, students indicate that they do not find it 
easy to understand content provided using audio methods. Even when the instructors use audio methods, content is not easy to understand and thus making it difficult to refer to it. On the other hand, instructors find it easy to deliver content using audio methods. They also think that students learn more with the use of these methods and find them to be good for reference by the students.

The high use of telephones in distance education emphasizes the fact that machines are very important in distance education as suggested by Peters (1994). They also create a dialogue between the learners and instructors which is an essential element in distance education (Moore, 1996). Video conferencing usage is not available hence making it hard to show the relationship between ICT and distance education. However, Projectors are available and are used mostly with face to face sessions. They therefore bring out Peters' (1994) Theory since they are machines and also structure and dialogue (Moore, 1994) are emphasized here. Overall, the available synchronous ICT and as used in Ugandan universities, enhance distance education as predicted.

\section{Conclusion}

The opinions from Makerere University and Kyambogo University presented in this paper have various implications on the teaching and learning process in distance education. The discussion presents an overview of the meaning, implication and views of the respondents in both universities. The use of ICT in the enhancement of distance education is very essential if the process of learning and teaching is to be effective and efficient. This means that one cannot disintegrate ICT from distance education if one is to achieve what is advocated for in both Peters (1994) Industrialization of distance education Theory and Moore's (1996) Transactional Theory. Peters (1994) here suggests that ICT are really needed and are part of the industrialization process of distance education. It has also been discovered that to achieve autonomy of the learner, dialogue and a good structure, ICT are very important (Moore, 1996). From the findings of this study, we can conclude that:

1. The use of the telephone is paramount in distance education more especially the mobile telephone. This is a big step in the incorporation of ICT into distance education and it shows that there is always room for more ICT to be integrated into the program if we are to achieve industrialization and the dialogue advocated for in this kind of education.

2. Some ICT are not being used at all like video conferencing technology in the process of teaching and learning in distance education in Ugandan public universities. This is because they are not available or are inaccessible. Yet, in order to industrialize distance education (Peters, 1994) and to develop learner autonomy as per Moore's (1996) theory, some of these are the best ICT that can be exploited. Dialogue can also be created between the learner and the instructor using technology as video conferencing. 
3. Synchronous ICT are used mainly for interaction between students and students, students and instructors and instructors and instructors. This is probably due to their being able to provide a dialogue for real time communication. This direct exchange between and within both parties concerned with distance education make its transaction easy and clear. At the same time, to achieve that needed dialogue, more industrialization through the use of ICT is essential.

Putting into consideration the findings of this study, in order to improve on the utilization of ICT in the enhancement of distance education, the following recommendations can be made. To the policy makers, it is recommended that all the available ICT on the market that are expected to improve learning should be made available to institutions of learning for easy exploitation. This means that, all institutions that provide distance education should be equipped with technology that is fully supported for its easy transaction as suggested by Peters (1994). In practice, it is recommended that instructors involved in distance education should have knowledge on the use of different technology and should always be ready to learn whenever a need arises. This can be achieved through training programmes on the use of the distance education technologies. All the available technology at the disposal of instructors should be exploited in the delivery and development of distance education to the maximum. This will make it easier for the learners to learn its use and use it as expected. Again, synchronous ICT would be the best to consider since they allow real time communication between the learners and instructors. With respect to research, more empirical research should be done on the extent and strength of the relationship between ICT utilized and distance education. Also research on the trends in distance education and ICT in Uganda is recommended in addition to comparative studies with other African Universities.

\section{References}

Aguti, J.N., Fraser, W.J.: Integration of Information Communication Technologies (ICTs) in the distance education Bachelor of Education program, Makerere University Uganda. Turkish Online Journal of Distance Education- TODJE (2006),

http: //tojde.anadolu.ed.tr/tojde18/about.html (retrieved on April 30, 2007)

Bbuye, J., Mango, M.J.: Origin and Trend of Distance Education in Uganda. Journal of Social Sciences 1(3), 166-171 (2005)

Binns, F., Otto, A.: Quality assurance in open distance education- Towards a culture of quality: A case study of Kyambogo University, Uganda. In: Koul, B.N., Kanwar, A. (eds.) Towards a Culture of Quality, Perspectives on Distance Education, Commonwealth of Learning (2006)

Krejcie, R.V., Morgan, D.W.: Determining sample size for research activities. Educational and Psychological Measurement 30, 680 (1970)

Gudula, N.B.: Distance education and a realistic teacher education pedagogy in Uganda: impact of an ICT -supported learning environment. Unpublished PHD Thesis, University of Gent, Belgium (2006) 
Mayende, G.: Mobile Technologies to Support Discussion Groups within in Distance Education in Developing Countries, Software Engineering Group (2007), http: / / www . idi.ntnu . no/grupper/su/index . php3 ?file=su-diploma2007 / index. html (retrieved on December 24, 2008)

Moore, M.: Theory of Transactional Distance. In: Keegan, D. (ed.) Theoretical Principles of Distance Education, pp. 22-38. Routledge, London (1996)

Ouma, A.P.: A national Distance Education (DE) solution for Uganda: Innovative Application of Digital ICT s to Overcome the Barriers of the Existing Digital Divide. Paper Presented in University of South Africa, The Inter-University Council for East Africa Kampala Uganda (2003)

Perraton, Robinson, H.: Teacher education guidelines: using open and distance learning. In: UNESCO, Paris, France (2002)

Peters, O.: Otto Peters on Distance Education: The Industrialization of Teaching and Learning. Routledge, New York (1994),

http: / / books.google.co.ug/books?id=rrvp2_IlHKAC

(retrieved on January 5, 2009)

Saint, W.: Tertiary distance education and technology in sub-Saharan Africa (1999), http: / /www. Adeanet. org (retrieved on May 15, 2007) 